\title{
Whipple's Operation Under Lumber Epidural Analgesia and Sedation
}

\author{
Dr. Zia Arshad ${ }^{1}$, Dr. Haider Abbas ${ }^{2}$, Dr. Ritu Verma ${ }^{3}$, Dr. Sulekha Saxena ${ }^{4}$, Dr. \\ Vikas ${ }^{5}$, Dr. Jaishri Bogra ${ }^{6}$. \\ 1Assistant Professor, Department of Anaesthesia, KG's MU, Lucknow, India. \\ 2 Associate Professor, Department of Anaesthesia, KG's MU, Lucknow, India. \\ 3Assistant Professor, Department of Anaesthesia, KG's MU, Lucknow, India. \\ 4,5MD Student, Department of Anaesthesia, $K G$ 's $M U$, Lucknow, India. \\ 6 Professor and Head, Department of Anaesthesia, KG's MU, Lucknow, India.
}

\begin{abstract}
Whipple's operation can be carried out either under general anaesthesia or continuous epidural anaesthesia with sedation.

We report three cases that were managed successfully and we found that the combination of lumbar epidural analgesia with sedation is safer and beneficial as compared to those who undergo Whipple's operation under general anaesthesia.

For the last three decades epidural analgesia has been the part of anaesthesia practice. Epidural analgesia can be a useful method of pain management various situations. It facilitates early mobilization and also avoids perioperative pulmonary complications especially after major thoracic or upper abdominal surgeries.

The combination of continuous epidural analgesia with sedation has many advantages in prolonged major upper abdominal surgeries.
\end{abstract}

Keywords- Whipple's operation, general anaesthesia, continuous epidural anaesthesia, sedation, upper abdominal surgery.

\section{Case Report}

We present 3 cases where regional anaesthesia technique combined with sedation for whipple's operation was employed successfully. Three patients with obstructive jaundice secondary to periampullary carcinoma posted for whipple's surgery. The diagnosis was confirmed by blood biochemistry, CT scan, ERCP and biopsy. General physical and systemic examination and vital parameters was essentially the same in all the patients. On pre-anaesthetic examination, an informed consent was taken and patients were thoroughly explained about the procedure and technique of lumbar epidural anaesthesia.

After taking the patients in operation theater, patient were monitored for HR, BP, ECG, SpO2 and temperature. Intra Venous access was secured with $18 \mathrm{G}$ cannula on the dorsum of hand and preloading was done with ringer's lactate solution $10-15 \mathrm{ml} \mathrm{kg-1}$. under full aseptic precaution an epidural catheter was inserted in the epidural space at L1-L2 level. The tip of catheter was advanced to T4. A test dose of $3 \mathrm{ml}$ of $2 \%$ xylocaine with adrenaline $5 \mu \mathrm{g} \mathrm{ml}-1$ was given after insuring correct placement the bolus dose of local anaesthetics $(10 \mathrm{ml}$ of $2 \%$ lignocaine and $10 \mathrm{ml}$ of $0.5 \%$ bupivacaine and 50 micro g of fentanyl) was given followed by bolus dose of $6 \mathrm{ml} 0.5 \%$ bupivacaine hourly. Central venous cannulation was done and CVP maintained between $8-10 \mathrm{~cm}$ of normal saline. Opioids were not used. Urine output monitoring was done and maintained between $1.5-2 \mathrm{ml} \mathrm{kg}-1 \mathrm{hr}-1$. Blood loss was adequately replaced by PRBCs, FFP's and other IV fluids. Average blood loss in all 3 cases was 2-3 liters. The duration of surgery was approximately 8 hours. Propofol infusion $10 \mathrm{ml} \mathrm{hr-1}$ was used in all cases for sedation along with midazolam @ $2 \mathrm{ml} / \mathrm{hour}$. Vital signs were monitered and maintained through out intraoperative period. All patients were fully conscious, oriented and with stable vitals. Postoperative $\mathrm{x}$-ray Chest was normal in all cases. Postoperative pain relief was given with lumber epidural infusion. Bowel sounds were audible on 3rd postoperative day. Biochemistry, haematological and Blood Gas parameters was within normal limits. Patients remained comfortable, without pain and were discharged on 3-4th postoperative day from the ICU. epidural catheter was removed before discharge. All the 3 patients were ambulatory and with no complaint of pain. 


\section{Discussion}

Pancreaticoduodenectomy Originally performed in a two-step process, Whipple refined his technique in 1940 into a one-step operation. Using modern operating techniques, mortality from a Whipple procedure is around five percent in the United States (less than two percent in high-volume academic centers. ${ }^{[1]}$ The lumbar epidural anaesthesia is not often used alone any major upper abdominal surgery. There are some reports that combination of thoracic epidural anaesthesia and sedation for most types of thoracic and upper abdominal surgeries, allowing intraoperative and postoperative analgesia to be controlled by this regional anaesthetic technique. It appears to improve the outcome of patients undergoing major upper abdominal surgeries such as pancreaticoduodenectomy (Whipple's operation), hemi-colectomy or total gastrectomy.

We use lumbar epidural without general anaesthesia. The bolus dose of local anaesthetics $(10 \mathrm{ml}$ of $2 \%$ lignocaine and $10 \mathrm{ml}$ of $0.5 \%$ bupivacaine and 50 micro g of fentanyl) followed by bolus dose of $6 \mathrm{ml} 0.5 \%$ bupivacaine hourly along with mild sedation with propofol and midazolam. For a prolonged effect, a continuous infusion of drugs may be employed. There is some evidence that an automated intermittent bolus technique provides better analgesia than a continuous infusion technique, though the total doses are identical. ${ }^{[2][3][4]}$ There was no supplementation of narcotic analgesics during the surgery. No adverse effects were observed. All the three patients were kept well sedated with propofol infusion $10-20 \mathrm{ml}$ per $\mathrm{h}$ and midazolam infusion rate was 2 $\mathrm{ml} / \mathrm{hr}$. The use of epidural analgesia resulted in decreased duration of postoperative ileus, which was directly related with shorter duration of stay in ICU.

In conclusion, the lumbar epidural analgesia which is usually associated with satisfactory intraoperative and postoperative pain control, improves patient out-come in those undergoing major thoracic or upper abdominal surgeries. Continuous epidural infusion of local anaesthetics with fentanyl solution will be an ideal and effective technique for relief of pain with adequate maintenance of normal pulmonary function . ${ }^{[5]}$ Recent works suggest that the combination of opiods and local anaesthetics as an infusion, confers the advantages of both reducing toxicity and improving analgesia especially in the postoperative period identical. ${ }^{[6]}$ The patients receiving epidural analgesia experience faster recovery as judged by shorter postoperative and decreased ICU and hospital stay, resulting in significantly reduced hospitalization costs.

\section{References}

[1]. Fingerhut, A; Vassiliu, P; Dervenis, C; Alexakis, N; Leandros, E (2007). "What is in a word: Pancreatoduodenectomy or pancreaticoduodenectomy?". Surgery 142 (3): 428-9.

[2]. Lim Y, Sia AT, Ocampo C (2005). "Automated regular boluses for epidural analgesia: a comparison with continuous infusion". Int $J$ Obstet Anesth 14 (4): 305-9.

[3]. Wong CA, Ratliff JT, Sullivan JT, Scavone BM, Toledo P, McCarthy RJ (2006). "A randomized comparison of programmed intermittent epidural bolus with continuous epidural infusion for labor analgesia". Anesth Analg 102 (3): 904-9.

[4]. Sia AT, Lim Y, Ocampo C (2007). "A comparison of a basal infusion with automated mandatory boluses in parturient-controlled epidural analgesia during labor". Anesth Analg 104 (3): 673-8.

[5]. Burgess Fw, Anderson DM, Colonna D, Cavnaugh DG. Thoracic epidural analgesia with bupivacaine and fentanyl for postoperative thoracotomy pain. J Cardio Vasc Anesth 1994; 8: 420-424.

[6]. David AS, David SNB, Caleem McC. Postoperative analgesia using epidural infusion of fentanyl with bupivacaine. Anesthesiology 1995; 83: 727-737. 